\title{
Synthesis of Artistic Forms in Park and Garden Design
}

\author{
Tatyana Mamontova \\ Russian State Social University \\ Moscow, Russia \\ e-mail: tatunj@yandex.ru
}

\begin{abstract}
This article deals with the role of artistic forms and their synthesis in landscape design. The author also elaborates on the issues of symbols and semantics in landscape design.
\end{abstract}

Keywords - An artistic form is; Artistic image; Synthesis; Semantics; Park and Garden Design.

\section{INTRODUCTION}

Landscape design has always been a specific mixture of many arts and crafts. Objects of architecture and landscape design are created on the basis of organic interaction between the rules of harmony and the freedom of art. The design process of both architecture and landscape design objects is closely related to mathematical, physical, biological, compositional and other rules on the one hand; and to the psychology of perceiving volume, shape and space, symbols, images, imagination, and phantasy on the other. Mathematics, composition, psychology and semantics are the spheres of fundamental academic knowledge that underpins design and, regarding their profoundness, give space to creativeness. In other words, garden design is a complicated and multifaceted process connected with history and the future at the same time. It is a system developed in terms of time and space, that requires special attention [1].

However, nowadays landscape design interests mostly specialists in the history of architecture, with synthesis of artistic forms in the design, semantics of gardens not analyzed at all.

\section{ART FORM IN LANDSCAPE DESIGN}

Artistic form is relatively autonomous; it has its own immanent rules of development. However, social factors certainly affect artistic forms. The language of gothic, baroque, classicism, and impressionism was profoundly influenced by the socio-historical climate, sentiments and ideals of the epoch. Social and historical demands can be based on available materials and ways of their processing, scientific and technological progress (marble processing in the times of Michelangelo, the impressionist system of separate strokes, constructivists' metal constructions).

An artistic form is a way of expression and material existence in compliance with the rules of a certain form and genre of art. It also reflects the hierarchy of meanings from lower to higher. This general definition of a form can be specified in terms of a particular piece of art. Applied to a completed artwork, a form is: a unified complex of artistic means and devices aimed at expression of unique content.

Means of artistic depiction and expression are inclined to systemic structure, interdependence and, hence, can develop and improve on their own. Each form of art has its own rules organizing its specific means of expression.

Therefore, the same means of expression may perform different functions in different fields of art: lines in fine art and graphics, words in poetry and novels, intonations in music and poetry, colour in fine art and cinema, gestures in pantomime, dance and acting. Meanwhile, the principles of form creation in certain fields and genres may influence others. And eventually, a remarkable creative individual comes to establish new forms of expression.

Since designers are usually interested only in visual aspects of the garden, its semantic can be almost completely lost during both the restoration of historical parks and gardens and the establishment of new ones. Gardens and parks are merely regarded as "green architecture" objects in most cases. Losing the ability to "read" and establish gardens filled with symbols, and containing entire iconological systems and perceive them in the light of the "aesthetic climate" of the epoch, is related to a general trend of decline in the ability of iconological perception and elementary knowledge of traditional symbols and emblems on the whole during the last century. Our creative mind has lost the ability not only to understand, but also to be interested in symbolic and allegoric meanings of park and gardening elements. However, the need for green zones in modern cities cannot be overestimated [5]. First of all, it is a matter of moral and physical health. Secondly, nowadays society is in need of unity with nature more than ever before, it desperately needs to perceive and accept nature; "free" nature is much more in demand than an artificial one [2].

\section{The Symbolic Meaning, The Semantics OF LANDSCAPE ART}

The history of landscape gardening has seen many symbolic systems, for a garden or a park is a peculiar cultural phenomenon appealing to its visitor not only by means of its separate components, but also by establishing an aesthetic system whose content requires specific definition and analysis. Gardening motives as well as many other cultural 
phenomena repeats with the time in most cases - even if they disappear, they return after a short period of time. It is only the meaning of certain elements that can change; as well as the plot, which is usually affected by the "aesthetic climate" of the epoch. The artistic form also changes, along with the emotional patterns of different generations. A garden always reflects some philosophy, aesthetic visions of the world, and people's attitude to nature; it is a micro-world in its ideal implementation [3].

There are two types of garden semantics. The first type can be almost adequately expressed or explained in words. These are various allegories, symbols of notions, events reflected in commercial art and directly in words. The garden "speaks" and is "wordless" at the same time. The garden is in need of somebody who will speak for it. Therefore, the garden addresses thoughts and creativity. The second type is about the connection of gardening elements with certain styles and notion systems. This concerns the style of the entire garden or its parts, its general sentiment, sights and the associations it awakes. This second semantic type requires a deeper analysis.

\section{TYPES OF ARTISTIC IMAGES IN LANDSCAPE DESIGN DURING THE SYNTHESIS OF ART FORMS}

While organizing gardens and parks, a premium should be put on the image of the future object. Sometimes this image is not presented quite explicitly. Analyzing park and gardening objects, we point out a typological range of artistic images inherent in this form of art:

- "Country image". The basic principle is to reflect the spirit of a country by means of the distinguishing features of the landscape organization in this region. A range of landscape elements and composition devices are used to make a visitor recall the associative array connected with a certain geographic point.

- "Mythological" image is influenced by legends, myths and fairy-tales of different folks.

- "Ethnic" image is based on aesthetic preferences typical of a certain nation. This image can be influenced by either secular of religious culture. Symbols within the culture can be represented in such garden elements as dendrology, coloristic, sound landscape and aromatic composition. National ornaments can be the main theme in the entire composition, or the picture of flower beds, decorative grates, etc.

- "Landscape genetic" images are established on the basis of association with the powers of nature such as water, fire, wind, etc. This type includes stylized or naturalized presentation of different landscape patterns: "water" landscape, "mountain", etc.

- "Poetical" image - inherent in romantic parks and gardens. This type can be identified by sentimental names of the landscape architecture elements.
- "Urban" image in landscape architecture objects semantically reflects the problems of urbanization affecting the environment and interaction between them.

\section{CONCLUSION}

To sum up, a garden is a story. a scenario designed to bring out certain emotions, thoughts, contemplation in the visitors; it is not a dead, but a functioning piece of art. It is a place to walk, relax and have a good time - as is customary in each epoch. The garden has always "asked" for different things; suggested different thoughts and provided differently organized backgrounds for these thoughts. In a sense, gardens and parks create "ideal" conditions for the interaction between humans and nature - "ideal" for each period of human history, each creator of park and gardening masterpieces. [4]

Seeking new artistic devices and images, one needs to look around attentively. Polluted, shrinking and recreationunfriendly zones in big and average cities do not provide enough free space for the recreation of the population. There are various problems in this sphere: grounds growing in price, restrained urban conditions, unfavorable environment, and contradicting social and private interests. City dwellers are in need of high-quality park and garden zones, but there are no appropriate financial, social, material and cultural conditions to meet their demands.

We should turn to the existing experience to solve these and other problems. Sustainable urban development is impossible without improving the provision of public amenities including the reconstruction of green zones of cities and development of new ones.

Attitude to the past shapes one's national identity, for each and every person bears the past as well as the national character.

A person is a part of society and its history. It is historical memories and poetical associations that make the nature of parks and gardens more human, which distinguishes them. We should value parks not only for the things they contain now, but also for those they used to.

\section{REFERENCES}

[1] Ilyinskaya N.A. Restoring Historical Objects of Landscape Architecture. - SPb., 1993.

[2] Mikhaylov A.V. Johan Huizinga in Cultural Historiography // Huizinga, J. The Autumn of the Middle Ages. - M.: Nauka, 1988.

[3] Pavlenko L.G. Landscape Design. Landscape Gardening. - Rostovon-Don: Feniks, 2005.

[4] Chyorniy V.D. Russian Medieval Gardens. Classification Experience. - M.: Handwritten Landmarks of Ancient Rus, 2010.

[5] Smolova L.V. Key Factors of Saint-Petersburg Population's Satisfaction with the Environment // Proceedings of the 10th International Academic Conference "Psychological and Social Work in Modern Society: Problems and Solutions", Saint-Petersburg, April 19-21, 2012. SPbGIPiSR, 2012. 